\title{
Optimizing the Use of Antibiotic Agents in the Pediatric Intensive Care Unit: A Narrative Review
}

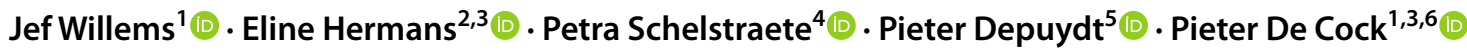

Accepted: 24 October 2020 / Published online: 10 November 2020

(c) Springer Nature Switzerland AG 2020

\begin{abstract}
Antibiotics are one of the most prescribed drug classes in the pediatric intensive care unit, yet the incidence of inappropriate antibiotic prescribing remains high in critically ill children. Optimizing the use of antibiotics in this population is imperative to guarantee adequate treatment, avoid toxicity and the occurrence of antibiotic resistance, both on a patient level and on a population level. Antibiotic stewardship encompasses all initiatives to promote responsible antibiotic usage and the PICU represents a major target environment for antibiotic stewardship programs. This narrative review provides a summary of the available knowledge on the optimal selection, duration, dosage, and route of administration of antibiotic treatment in critically ill children. Overall, more scientific evidence on how to optimize antibiotic treatment is warranted in this population. We also give our personal expert opinion on research priorities.
\end{abstract}

\section{Key Points}

Optimizing antimicrobial treatment should focus on the optimal selection, dosage, and duration of antimicrobial treatment, via the optimal route of administration.

In critically ill children, little research has been conducted to increase the appropriate use of antibiotics.

Pieter De Cock

pieter.decock@uzgent.be

1 Department of Pediatric Intensive Care, Ghent University Hospital, Gent, Belgium

2 Department of Pediatrics, Ghent University Hospital, Gent, Belgium

3 Heymans Institute of Pharmacology, Ghent University, Gent, Belgium

4 Department of Pediatric Pulmonology, Ghent University Hospital, Gent, Belgium

5 Department of Intensive Care Medicine, Ghent University Hospital, Gent, Belgium

6 Department of Pharmacy, Ghent University Hospital, Gent, Belgium

\section{Introduction}

The development of antibiotics has revolutionized modern medicine, not only by offering a cure for common potentially life-threatening communicable diseases such as communityacquired pneumonia, but also by facilitating surgical and oncologic therapies in which nosocomial infections are a major cause of morbidity and mortality [1].

Although potentially life-saving, antibiotic usage is not without problems. Adverse reactions, albeit most often mild, are a common reason for medical consultation, but more severe adverse reactions such as Stevens-Johnson syndrome may occur as well. Use of broad-spectrum antibiotics in an in-hospital setting is also strongly linked to Clostridioides difficile infections, a common reason for increased length of hospital stay (LOS), often in vulnerable patients [2]. The impact of broad-spectrum antibiotic use on the gut microbiome, with possible links to development of auto-immune diseases, is a hot topic in research [3]. These adverse effects are rarely discussed with patients prior to initiation of antibiotic treatment [4].

The most important adverse effect, however, is the occurrence of antibiotic resistance, both at a patient level (risk of developing life-threatening secondary infections caused by these organisms) and at a population level (spreading of colonization with resistant strains may reduce the effectivity of certain antibiotic drug classes in a defined population). Generally, antibiotic resistance is rising [5]. The increasing 
use of carbapenems and glycopeptides (so called reserve antibiotics) may be attributed to increasing antibiotic resistance. Moreover, colonization with carbapenem-resistant Gram-negative bacteria in the gut microbiome has been documented to occur after only very brief exposure to these antibiotics [6].

Medical costs are soaring due to antibiotic resistance, with excess costs estimated to be as high as $€ 85$ trillion/ year by 2050. It is considered to be one of the biggest global health threats, expected to result in 10 million attributable deaths by that year [7]. Tackling antibiotic resistance has become a priority for the World Health Organization (WHO) [8].

Multidrug-resistant Gram-negative (MDRGN) bacteria are the clinically most important resistant bacteria in children admitted to the Pediatric Intensive Care Unit (PICU), with extended-spectrum $\beta$-lactamase-producing Enterobacterales (ESBL-Ent), mainly Escherichia coli strains, increasingly causing severe infections [9-11]. They usually occur in children with chronic conditions, but may also be found in otherwise healthy children with recurrent infections or previous antibiotic exposure. Adequate antibiotic treatment for these children may only be possible once results of susceptibility tests are available. Carbapenem-resistant Enterobacterales (CRE), usually Klebsiella or Enterobacter species, are found in the same populations, usually in the PICU. Outbreaks with multidrug-resistant (MDR) Acinetobacter species have been documented in neonatal intensive care units (NICU) [12]. Microorganisms that are already intrinsically resistant (e.g., Pseudomonas species) may acquire resistance to multiple $\beta$-lactams, including carbapenems, causing major therapeutic problems in critically ill children, and also warranting draconic infection control measures to limit spread [13].

As for the Gram-positive bacteria, methicillin-resistant Staphylococcus aureus (MRSA) has emerged in pediatric practice since 1990. Though incidence in the general population of the EU has decreased significantly between 2013 and 2016 [14], resistance to alternative antibiotic treatment is rising elsewhere [15].

Since infections occur in a large proportion of PICU patients, the use of broad-spectrum antibiotics is very common in this population. The largest point prevalence study so far, including 38 PICUs (both general and cardiac) in 23 countries, revealed antibiotic usage in $56 \%$ of PICU patients, of which the vast majority was treated with parenteral antibiotics and 50\% with combination therapy [16].

Antibiotic stewardship (AS) encompasses all initiatives to promote responsible antibiotic usage. Its main goals are to guarantee adequate treatment of infections and to reduce inappropriate antibiotic use. This necessity has acquired a manifest place in medical thinking, firstly in adult medicine [17]. Yet, in critically ill children, inappropriate antibiotic prescribing ranges up to $60 \%$ (mainly overly broad spectrum and wrong dosage) and, as such, the PICU represents a major target environment for antibiotic stewardship programs (ASPs) [18].

AS is commonly defined as 'the optimal selection, dosage, and duration of antimicrobial treatment, via the optimal route of administration' that results in the best clinical outcome for the treatment or prevention of infection, with minimal toxicity to the patient and minimal impact on subsequent resistance [19]. In this narrative review based on a literature search (MEDLINE and PubMed database) completed in June 2020, we sought to summarize recent advances and emerging perspectives for AS in the PICU.

\section{Right Drug}

\subsection{General}

When a clinically important infection is suspected, the first question is 'would this child require antibiotic treatment, and if so, which antibiotic class is to be chosen?'. Especially in young children with fever, in whom viral infections not requiring antibiotic treatment are common, the accuracy of clinical symptoms is poor [20].

The first goal of AS is to adequately treat serious bacterial infections (SBIs), comprising blood stream infections (BSIs), meningitis, pneumonia, and urinary tract infections, with aggressive empirical antibiotic therapy. In critically ill children with SBI, delayed empirical antibiotic therapy increases mortality and prolongs organ dysfunction. This risk increases significantly once antibiotic treatment is delayed for more than $3 \mathrm{~h}$, and then again with every additional hour [21, 22]. However, when subsequent diagnostics cannot confirm infection and discontinuation of antibiotic treatment may be indicated, this often does not happen [23, 24].

Moreover, antibiotics are commonly prescribed or continued when viral disease is proven, and even in non-infectious diseases without evidence of bacterial infection, such as severe asthma [25]. However, the suspicion of a bacterial co-infection in proven viral disease [most often respiratory syncytial virus (RSV)] may warrant early antibiotic treatment, especially in critically ill infants $<3$ months old [26]. Also, in these patients, timely discontinuation should be advocated when diagnostic evidence cannot reveal any sign of bacterial infection.

The role of the clinical laboratory is vital. Biomarkers may help distinguish patients with SBIs rapidly, guiding decision making on whether to start, continue, or discontinue antibiotic treatment. C-reactive protein measurement and white cell counting have been established for a long 
time, with good sensitivity but poor specificity regarding bacterial infections [27]. The added value of serial measurement of procalcitonin (PCT) levels has been demonstrated in adults, where a strategy for early discontinuation of antibiotic treatment has shown efficacy [28]. The role of PCT in critically ill children is controversial. It may have an added value in distinguishing bacterial from non-bacterial infectious disease in young febrile infants [29]. In a PICU population, neither single nor serial measurements could predict presence or absence of bacterial infection with enough certainty to start or withhold antibiotic treatment [30]. PCT has been extensively studied in critically ill children after congenital heart surgery, where it failed to distinguish postoperative infection from inflammation [31].

Advances in molecular biology have the potential to shorten time to identification of pathogens and to radically improve AS. Rapid polymerase chain reaction (PCR) testing for respiratory viruses has significantly increased the diagnostic yield compared with immune fluorescence testing. However, the availability of positive PCRs for respiratory viruses in mechanically ventilated babies in the PICU does not appear to impact antibiotic prescribing practices, exposing different behavioral mechanisms determining prescription by PICU physicians [32]. In less ill hospitalized children with acute respiratory illness, introduction of a rapid respiratory panel seems to have more impact, with reduced antibiotic duration and LOS [33].

Molecular diagnostic tools identifying multiple infective agents have been developed not only in respiratory samples, but also in blood, cerebrospinal fluid (CSF), urine, and feces [34-36]. Rapid blood culture diagnostics, in which rapid multiplex PCR is performed on positive blood culture bottles, may result in earlier accurate diagnosis, shorter time to adequate antibiotic treatment, and earlier de-escalation of empirical treatment, especially when AS teams are involved, as documented in an RCT in a large mixed adult/pediatric and (P)ICU/ non-(P)ICU population. However, impact on patient outcome could not be proven [37]. Specific pediatric data are scarce, with only a single study documenting a positive impact on antibiotic prescription patterns in S. aureus BSIs [38]. With new tests rapidly becoming available, the complexity of interpretation increases, warranting close communication between microbiologist and clinician in order to avoid unnecessary testing and to ensure that an adequate therapeutic response follows $[39,40]$.

When an SBI is suspected, empirical antibiotic therapy is selected based on which micro-organisms are presumed to have caused the infection. Practice guidelines for the choice of antibiotic drugs in common bacterial infectious emergencies (such as sepsis, pneumonia and meningitis) are rarely based on evidence but rather on clinical experience and observational studies [41-44]. Current knowledge regarding local antibiotic resistance is crucial. These may differ significantly between different regions, age groups, and healthcare centers. Institutional antibiotic resistance patterns need to be monitored as they should guide therapy [45]. Knowledge of the physicochemical properties of the antibiotic that allow drug penetration at the site of infection is crucial as well. For instance, antibiotics used for treatment of bacterial meningitis need to penetrate into the CSF.

Empirical therapy should account for the risk of antibiotic resistance, especially in hospital-acquired infections (HAI). Subsequently, antibiotic de-escalation (ADE) should be considered once microbiology results are available. ADE can be achieved in different ways: by replacing one antibiotic by another with a narrower spectrum, by reducing the number of antibiotics in case of combination therapy, or by discontinuation of antibiotics. No uniform definition of ADE is available [46]. Using this strategy, the aim is to reduce the antibiotic pressure and as such the selection of resistant bacteria. ADE is considered as a key intervention in ASPs [41] but it is only performed in a minority of adult ICU patients [47]. Important controversies regarding ADE do exist. Effects on bacterial resistance have not been demonstrated so far. Studies in adult patients have revealed that performing ADE was associated with an increase in antibiotic duration, which could be counterproductive when aiming for a reduction in antibiotic exposure [48]. PICU data are currently lacking.

The following sections focus on some common SBIs in PICU, both community and hospital acquired. A problem in all of these is the lack of uniform diagnostic criteria, leading to inconsistent diagnostics, categorization, and approaches $[49,50]$.

\subsection{Community-Acquired Infections in the PICU}

Infants younger than 3 months presenting with fever of unknown origin represent a group at increased risk for SBI. While awaiting results from diagnostic work-up and cultures, empiric antibiotic treatment is usually started early. The combination of IV ampicillin and gentamycin, or alternatively third-generation cephalosporins and ampicillin, provides good cover for the micro-organisms detected in a large prospective observational study [51].

For childhood bacterial meningitis, third-generation cephalosporins have proven their clinical efficiency for three decades [52]. Vancomycin is a valuable option for treatment of bacterial meningitis caused by resistant Streptococcus pneumoniae [53]. Other drug classes (carbapenems and fluoroquinolones, amongst others) have an adequate spectrum and meningeal penetration as well, but are less extensively studied.

Invasive group A streptococcal infections (mainly Streptococcal toxic shock syndrome and severe skin and soft 
tissue infections) cause significant morbidity and mortality in previously healthy children. Most Streptococcus pyogenes species are susceptible to penicillin. However, prospective observational studies in a mixed pediatric/adult population have shown reduced mortality and morbidity when clindamycin was added to the $\beta$-lactam antibiotic treatment, and a further positive trend has been noted when immunoglobulin therapy was also used [54].

Community-acquired pneumonia (CAP) remains the leading cause of death in $<5$-year-old children worldwide [55]. About $12-20 \%$ of children with CAP require PICU admission. Though viral disease is very common, antibiotic treatment is a cornerstone of treatment [56]. For those children requiring mechanical ventilation, delayed treatment with antibiotics is independently associated with adverse outcomes (longer duration of mechanical ventilation, increased PICU, and hospital LOS) [57]. Multiple guidelines for empirical antibiotic therapy exist, all with low levels of evidence. In regions with high susceptibility rates to penicillin for $S$. pneumoniae, amoxicillin remains the first-choice antibiotic [58]. Various randomized controlled trials (RCTs) comparing different antibiotic regimens have been conducted, all yielding similar efficacy outcomes for macrolides, amoxicillin, amoxicillin/clavulanic acid, and cephalosporins $[59,60]$. As bacterial co-infection in children with influenza can lead to serious morbidity and is commonly caused by S. aureus, treatment with amoxicillin/ clavulanic acid is recommended in this group of patients. Though the use of macrolides is advocated in atypical pneumonia in most guidelines, there is to date very little evidence to support this [61]. Altogether, very little research has been conducted in critically ill children.

\subsection{Hospital-Acquired Infections in the PICU}

The PICU environment has a high rate of HAI (up to 23\%), due to frequent invasive procedures and use of medical devices (central lines, endotracheal tubes) and patient factors (immature immune system, immune deficiencies) [62]. They have a major impact on morbidity, LOS, and hospital costs [63]. The two most frequent forms of HAI are catheterassociated bloodstream infections (CA-BSI) and pneumonia [64-67]. Other HAI encountered in the PICU include surgical-site infections and catheter-associated urinary tract infections. Generally, incidence rates of HAIs in the PICU are decreasing, due to increased awareness and knowledge of prevention strategies [68].

Whenever CA-BSI is suspected, empirical treatment with broad cover for Gram-positives ( $S$. aureus and coagulasenegative staphylococci are the most frequently reported pathogens [69]), and also, though less frequently found, Gram-negatives (notably also Pseudomonas aeruginosa), is started. If infection with MDRGN is likely, carbapenems are indicated. If Candida infection is likely (e.g., after longduration antibiotic courses, immunosuppression, or multisite candida colonization), empirical antifungal treatment is indicated [70].

Pneumonia, both community- and hospital-acquired, accounts for up to $50 \%$ of antibiotic use in PICUs [71]. Amongst hospital-acquired pneumonia (HAP), ventilatorassociated pneumonia (VAP) is the most common. Incidence is lower in pediatric than in adult patient series, but data are limited $[72,73]$. The case definition of VAP is subject to debate, with both clinical signs (worsening ventilation conditions, fever, and appearance of purulent secretions) and laboratory findings (white cell counts and culture on respiratory samples) being important though imprecise diagnostic factors [74]. As colonization of an endotracheal tube occurs quickly, the mere presence of bacteria in surveillance cultures from endotracheal aspirates does not warrant antibiotic treatment [75]. Of note, $>30 \%$ of Enterobacterales in endotracheal aspirates may be MDR, with a clear link to previous antibiotic exposure of $>7$ days [76]. Studies in adults revealed that only very recent cultures (from endotracheal aspirates taken $\leq 2$ days before onset of VAP) are reliable in predicting the responsible pathogen [77].

Once VAP is diagnosed, antibiotic treatment should not be delayed [78]. Treatment for 'early' VAP (1-4 days after intubation) will focus on similar micro-organisms as in CAP, treatment for 'late' VAP (occurs more frequently, $>4$ days after intubation) should cover $P$. aeruginosa, Klebsiella pneumoniae/oxytoca, Enterobacter spp, in addition to $S$. pneumoniae and $S$. aureus. Antibiotic resistance is a major problem in this group [69, 79].

HAP in non-ventilated patients may be acquired inside or outside the PICU and usually has a more benign course and is less frequently due to MDR organisms [80]. Adult guidelines with algorithms allowing tailored antibiotic treatment for these patients are available [81]. Pediatric guidelines are currently lacking.

\section{Right Duration}

\subsection{General}

When little evidence is available regarding the 'right drug', even fewer studies are available regarding the 'right duration' of treatment. Most guidelines are based on expert opinion. As occurrence of antibiotic resistance is related to the duration of antibiotic treatment, early discontinuation may offer an opportunity for AS [82]. The paradigm of 'once you start an antibiotic treatment course, you have to continue the full treatment duration to avoid emergence of antibiotic resistance' appears to be false [83]. However, 
PICU physicians rarely consider shortening the duration of antibiotic therapy even when the child is getting better [24]. As described above, clinical laboratory support with serial biomarker testing and rapid molecular testing has the potential to alter not only the choice but also the duration of antibiotic therapy.

Electronic prescribing (EP) of medication has become common practice in PICUs. It has demonstrated increased medication safety by reducing prescription errors [84]. EP may include an 'auto-stop' strategy, allowing targeted antibiotics to be prescribed for a predefined duration before they have to be re-evaluated [85].

\subsection{Community-Acquired Serious Bacterial Infections}

Acute bacterial meningitis is treated with intravenous antibiotics for 7-21 days, with the exact duration depending on the responsible micro-organism and the clinical response. This duration is based on clinical experience and expert opinion rather than on evidence [42]. In a large multicenter RCT in children with acute purulent bacterial meningitis, either caused by S. pneumoniae, Haemophilus influenzae type b or Neisseria meningitidis, and with good clinical response after 5 days of intravenous ceftriaxone treatment, no difference in outcome could be seen when treatment was stopped compared with children subsequently treated for another 5 days [86].

For severe CAP, most guidelines recommend treatment for a minimum of 7 days $[58,87]$. High quality RCTs comparing shorter courses with 'standard duration' are lacking [88]. For complicated CAP (empyema, necrotizing pneumonia), even less evidence is available and generally longer treatment courses are advocated.

\subsection{Hospital-Acquired Serious Bacterial Infections}

For CA-BSI, the goals of antibiotic treatment are to treat infection and to salvage the catheter if feasible. For longterm catheters, recommended duration depends on whether the catheter is removed and on the pathogen (range 5-14 days when catheter is removed vs 7-14 days if not). No RCTs are available, many data are derived from adult studies [89]. For short-term central venous catheters, salvaging the catheter may be less important and guidelines such as those issued by the Infectious Diseases Society of America (IDSA) support catheter removal as a first step. Antibiotic lock treatment, involving instilling an antibiotic solution into the central line with regular changing, can be seen as an adjunctive therapy in children who lack absolute criteria for line removal, especially for long-term catheters. Once again, only adult data are available [90].

For VAP, no specific pediatric data are available. In adult literature, a standard 8-day antibiotic course is equivalent to a 15-day course, with shorter courses considered safe upon guidance by clinical resolution or serial biomarkers (PCT) $[28,91]$. A pragmatic approach for pediatric VAP would be to treat for 5 days with antibiotics in children with good initial response and 7-10 days if $P$. aeruginosa or MDRGN are isolated from cultures [92].

\section{Right Dosage}

Most antibiotics administered in the PICU are prescribed outside the terms of the product license (off-label) or even without market authorization (unlicensed use) [93]. The recommended dosing regimens for critically ill children are often empirically derived from adults, relatively "healthy" and/or older children. Simple algorithms extrapolate these dosing schemes based on body weight, height or body surface area [94]. Although antibiotic use in these patients is one of the key interventions in their treatment, current knowledge on the pharmacokinetics (PK) and pharmacodynamics (PD) of antibiotics in this population remains relatively limited. Many frequently used agents (e.g., ceftriaxone, ceftazidime, penicillin, flucloxacillin, metronidazole) even completely lack PK data in critically ill children. The PK studies that have been published report that conventional dosing strategies consistently fail to achieve the proper PK/ PD targets $[95,96]$. Specifically for $\beta$-lactam antibiotics, 95\% of a PICU study population had sub-therapeutic concentrations [97].

A dosing strategy that 'fits all' does not exist in the critically ill child. When deciding on a dosing schedule in these patients, it is imperative to realize that maturation and pathophysiology significantly impact the PK and thus the time-concentration profiles of these antibiotics. The high level of inter-subject variability in PK characteristics emphasizes the need for clinicians to implement specific and personalized dosing strategies.

\subsection{Pharmacokinetics in Critically III Children}

Growth and development have an impact on drug absorption, distribution, metabolism, and excretion (ADME) processes in children. The developmental changes in the ADME processes are dynamic. Especially in the first 2 years of life, rapid maturation significantly influences PK processes $[98,99]$. In addition to the maturational alterations, pathophysiological and treatment-induced changes in critically ill children can significantly impact drug disposition (Fig. 1) [95, 100-104]. The effect of these 
changes on the concentration-time profiles of antibiotics depends on their physicochemical properties (Table 1).

Intravenous administration of antibiotics is often the preferred route in PICU patients to avoid compromised bioavailability due to impaired drug absorption. It is estimated that delayed gastric emptying occurs in $50 \%$ of critically ill children [105]. Additionally, splanchnic hypoperfusion due to shunting of the blood flow to the vital organs, disease- and therapy-induced cholestasis, and intestinal atrophy can contribute to a delayed and/or reduced antibiotic absorption [106-109].

Increased capillary permeability and the consequently augmented third spacing increase the volume of distribution (Vd) of hydrophilic drugs (e.g., $\beta$-lactams, aminoglycosides, glycopeptides). On the contrary, the distribution of lipophilic antibiotics (e.g., macrolides, fluoroquinolones) is little affected by these vascular changes [101, 104, 110]. Hypoalbuminemia is a common condition in critically ill patients, as a consequence of the increased capillary permeability and liver dysfunction [111]. It causes an increase in the unbound fraction of highly protein-bound antibiotics, which may lead to altered distribution and elimination [104, 110]. An elevated urea concentration and $\mathrm{pH}$ changes, commonly seen in critical illness, both can affect the ionized fraction of the antibiotic and the binding affinity of the antibiotic to plasma proteins, influencing the distribution and thus $\mathrm{Vd}$ [112]. The penetration of antibiotics into the tissues, the target site for most antibiotics, is governed by tissue perfusion, passive diffusion, transport mechanisms, lipid solubility, and protein binding [104]. Current data from microdialysis studies in critically ill adults suggest that the antibiotic penetration into the interstitial fluid in tissue is impaired when compared with healthy volunteers [113-115]. Reports on the tissue PK in critically ill children are still lacking.

Inflammation appears to downregulate hepatic drug metabolism [116]. In general, hepatic dysfunction impacts the clearance of lipophilic antibiotics, as they are mostly cleared after hepatic metabolization [103]. In the absence of significant organ dysfunction, the hyperdynamic circulation in a systemic inflammatory response (SIRS) leads to increased renal perfusion and consequently increased clearance of hydrophilic antibiotics. This 'augmented renal clearance' is a less well appreciated phenomenon in clinical practice, but can lead to significant under-dosing [117]. On the other hand, in the presence of renal insufficiency, antibiotics primarily eliminated via the kidneys will have a
Fig. 1 Pathophysiological and treatment-induced alterations in critical illness that may impact antibiotic pharmacokinetics. CYP450 cytochrome $\mathrm{P} 450$, GFR glomerular filtration rate

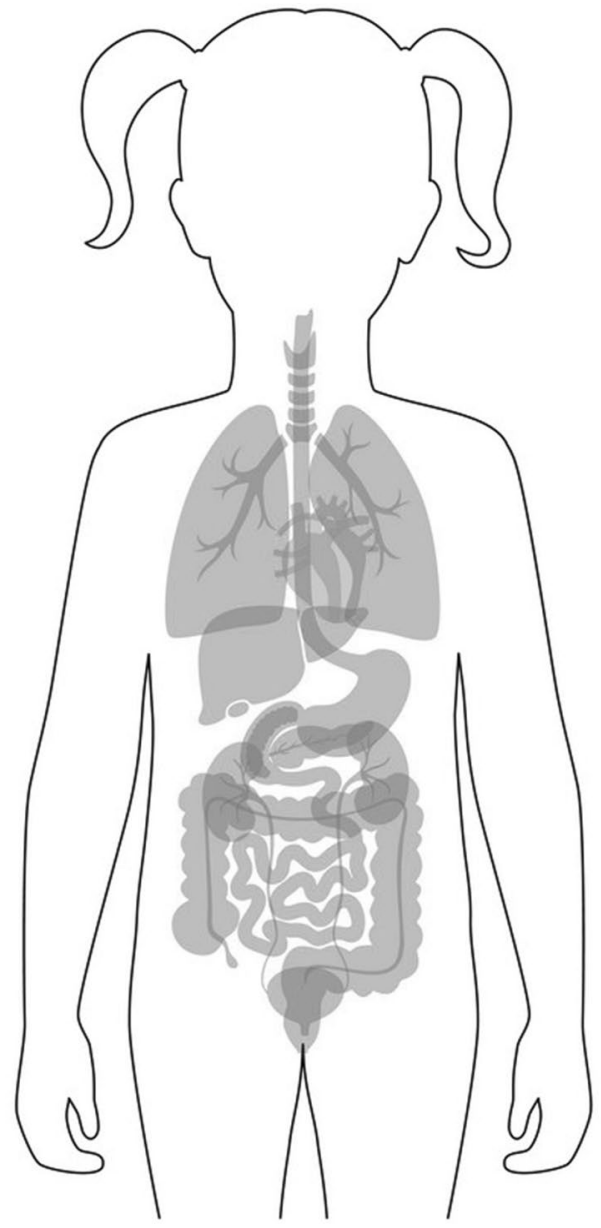

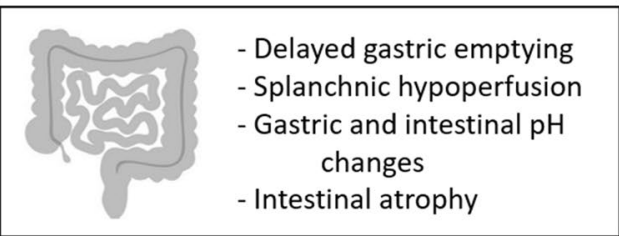
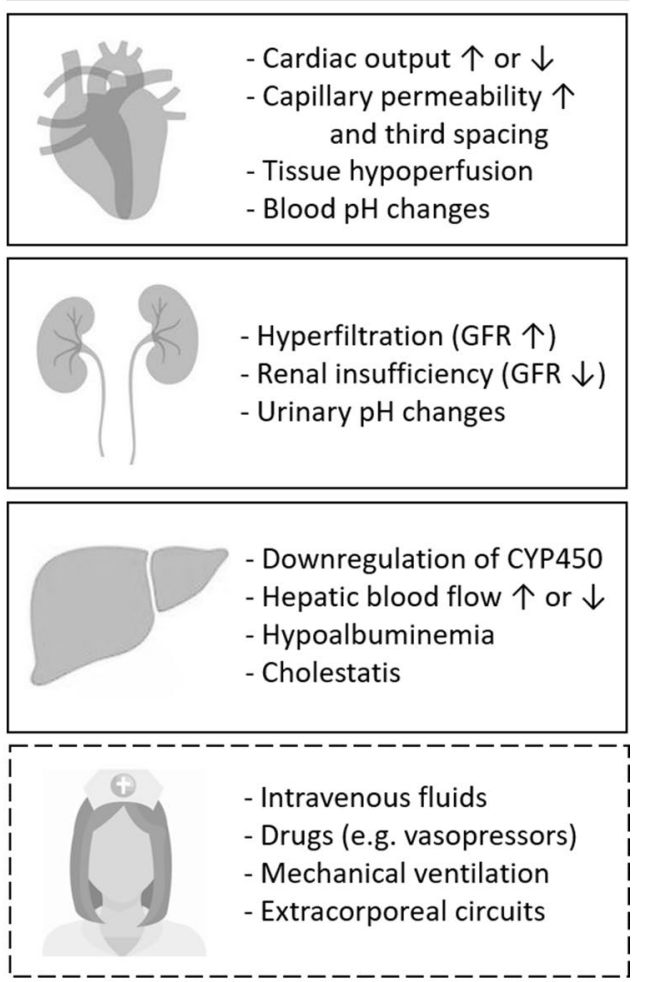
Table 1 The relationship between molecular and pharmacokinetic characteristics of antibiotics

\begin{tabular}{lll}
\hline & Hydrophilic antibiotics & Lipophilic antibiotics \\
\hline PK in healthy conditions & Intracellular penetration: low & Intracellular penetration: good \\
& Vd: Low & Vd: High \\
& Cl: $>>$ Renal & Cl: $>$ Hepatic \\
PK in critical illness & Vd: increased & Vd: Relatively unchanged \\
& Cl: increased (e.g., ARC) or decreased (e.g., renal dysfunc- & Cl: Unaffected or decreased depending \\
& tion) & on hepatic function and blood flow \\
PK in ECMO & Vd: increased & Vd: Increased or unaffected \\
& Cl: Unaffected or decreased (in renal function) & Cl: Likely decreased \\
PK in CRRT & Cl: Increased & Cl: unchanged or only mildly increased \\
Examples of antibiotic classes & $\beta$-Lactams, aminoglycosides, glycopeptides & Macrolides, fluoroquinolones \\
\hline
\end{tabular}

$A R C$ augmented renal clearance, $C l$ clearance, $C R R T$ continuous renal replacement therapy, $E C M O$ extracorporeal membrane oxygenation, $P K$ pharmacokinetics, $V d$ volume of distribution

diminished clearance, leading to a prolonged half-life and potential toxicity $[103,104]$. The administration of vasoactive drugs and intravenous fluid therapy can affect both antibiotic distribution and clearance, mainly through the resulting increase in cardiac output. Mechanical ventilation causes a decrease in cardiac output and hepatic and renal blood flow and thus potentially reduces the clearance of both hepatically and renally excreted antibiotics [118].

\subsection{Special Patient Populations in the PICU: Extracorporeal Circuits}

The use of extracorporeal circuits challenges the choice of the 'right dose' for the critically ill child even beyond the above-mentioned PK alterations. Extracorporeal membrane oxygenation (ECMO) and renal replacement therapy (RRT) are life-saving therapies with a very unique impact on drug disposition, depending on the treatment modality and system settings.

The ECMO system needs to be considered as an additional compartment when evaluating the PK of antibiotics. It causes an increase in the $\mathrm{Vd}$ of hydrophilic antibiotics, and results in decreased plasma concentrations due to hemodilution. The impact of hemodilution is expected to be largest in young children because of their low circulatory volumes. For lipophilic antibiotics, one of the drivers of the altered PK is drug sequestration in the circuit [119-121]. Renal dysfunction occurs in over $30 \%$ of patients on ECMO, leading to an altered elimination of renally excreted antibiotics $[119,120,122]$. The majority of the PK studies in ECMO were conducted in NICUs, but in recent years more data in older children and adults have become available. Antibiotic dosing recommendations in the presence of ECMO have been formulated [122]. In the case of vancomycin, for example, it is recommended to increase the initial dose and apply intensive therapeutic monitoring (TDM) in young patients due to the increase in $\operatorname{Vd}[122,123]$.

RRT is available in multiple modalities that all have a different impact on drug clearance. In a PICU setting, continuous renal replacement therapy (CRRT) is the most common form of RRT. Antibiotics with low molecular weight, low plasma protein binding, low $\mathrm{Vd}$, and renal clearance are predisposed to be eliminated from the body by CRRT [124]. CRRT-related clearance accounted for $63 \%$ of the total meropenem clearance in PICU patients [125]. For the frequently used antibiotics meropenem, piperacillin-tazobactam, and vancomycin, the effluent flow rate (net ultrafiltration + dialysate flow rate) appears to be the most reliable predictor of antibiotic clearance and should be taken into account when deciding on a dosing scheme [124, 126]. In contrast with ECMO, most studies on antibiotic PK in CRRT have been performed in critically ill adults and some antibiotic dosing recommendations have been formulated for this population [124]. To date, recommendations to guide antibiotic therapy during CRRT in children are not available.

\subsection{Pharmacodynamics in Critically III Children}

Antibiotics are distinct from other pharmacological therapies because the treatment is aimed at an infectious organism and not at any patient target per se. The PD characteristics of antibiotics relate drug concentrations to their ability to kill the pathogen and suppress the emergence of resistance. The minimum inhibitory concentration (MIC), which in vitro is the lowest concentration of the antibiotic required to inhibit visible growth of the organism, is the most widely used PD measurement to describe the potency of an antibiotic agent. Different antibiotic classes appear to demonstrate different kill characteristics on bacteria and thus, depending on the class, different PK/PD targets represent optimal 
bactericidal activity (Fig. 2). Three main targets are defined: ratio of the area under the drug concentration-time curve over MIC (AUC/MIC), time during which the concentration remains above the MIC (T>MIC) and ratio of the peak concentration over MIC $\left(C_{\max } / \mathrm{MIC}\right)[127]$.

\subsection{Strategies for Optimized Dosing in the PICU}

\subsubsection{Extended and Continuous Infusions}

Extended and continuous infusions may be a beneficial strategy when optimizing PK/PD target attainment of timedependent antibiotics. For $\beta$-lactam antibiotics, the minimum T>MIC should be $40-70 \%$, depending on the class of $\beta$-lactam antibiotic. Some clinical studies even suggest that higher exposures may be necessary to treat more severe infections [128]. In the case of piperacillin-tazobactam, PK studies in critically ill children determined that the traditional four doses per day, 30-min administration schedule often failed to maintain adequate plasma concentrations [129-132]. Monte Carlo simulations showed the need for more frequent, extended or continuous infusions to attain the target of $\mathrm{T}>\mathrm{MIC}$ of $50 \%$. Extended and continuous infusions of other $\beta$-lactam antibiotics (e.g., meropenem, cefotaxime) in a PICU setting have been observed to maximize the PK/ PD target attainment as well [96]. In the case of vancomycin, an AUC/MIC dependent antibiotic, a recent RCT in young infants comparing continuous and intermittent infusions demonstrated continuous infusions to be associated with earlier and improved target attainment [133]. Additionally, lower total daily doses and fewer dose adjustments were required to achieve therapeutic levels with continuous vancomycin infusions. Also, in older children, continuous vancomycin infusions appeared to be beneficial as they reached or exceeded the desired target concentration within 24-48

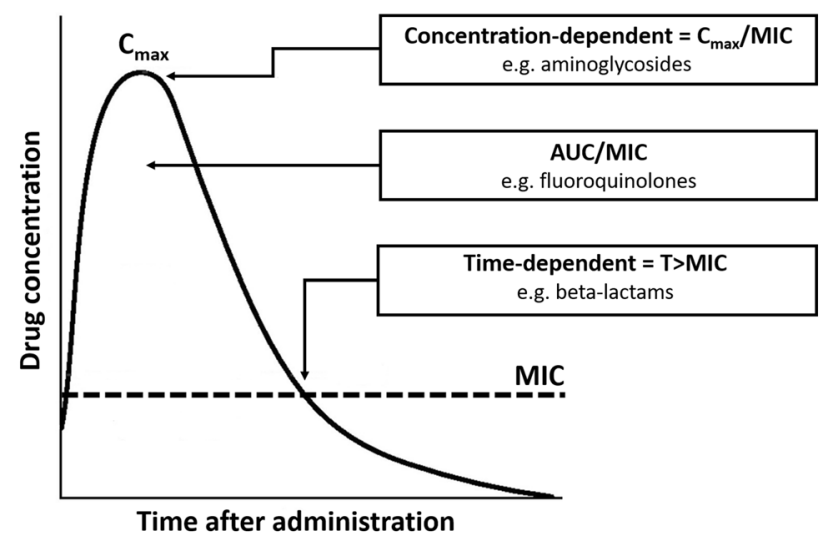

Fig. 2 Pharmacokinetic/pharmacodynamic parameters of antibiotics. $A U C$ area under the curve, $C_{\max }$ peak drug concentration, $M I C$ minimum inhibitory concentration, $T$ time $\mathrm{h}$ in the majority of the patients, after target concentrations could not be reached during intermittent therapy in the same patients [134].

Extended and continuous infusions have practical implications for clinical practice. When initiating an antibiotic therapy, a loading dose, adapted to the expected increase in $\mathrm{Vd}$ in the critically ill patient, is required to rapidly achieve target concentrations ("hit hard, hit early") $[135,136]$. Another potential pitfall is the incomplete administration of the drug due to the contribution of infusion-line dead space volume [135, 137]. Infusion volume and pump characteristics should be considered when deciding on a dosing scheme. It is recommended to use syringe pumps with a dead volume less than $2 \mathrm{ml}$ and to consider flushing the infusion line after completion of the administration. Other practical issues to take into account are drug stability at room temperature and drug-drug incompatibilities which sometimes may require the presence of a separate infusion line for the extended or continuous administration of the antibiotic [135].

Even though extended infusions improve the PK/PD target attainment of time dependent antibiotics, to date clinical trials have failed to show a clinical outcome benefit of this strategy in critically ill children or adults [138].

\subsubsection{Therapeutic Drug Monitoring}

TDM relies on the accurate and timely measurement of plasma antibiotic concentrations and the availability of a defined therapeutic range for the antibiotic to individualize the patient's dosing schedule during therapy. Historically, TDM has been used as a cautionary measure to prevent toxicity rather than to optimize antibiotic efficacy. For aminoglycosides and glycopeptides, TDM has become part of general practice with proven beneficial effect on clinical outcome. At this time, measurement of peak and trough concentrations are advised for aminoglycosides, starting from the first dose. Vancomycin intermittent dosing is individualized based upon the measured trough concentration, a practical surrogate marker for the AUC. During continuous infusions of vancomycin, a blood sample can be taken at any time once steady state is achieved [139, 140].

More recently, the use of TDM in other antibiotic classes has gained popularity, especially in specific patient populations (e.g., critical illness) [141-143]. Traditionally, $\beta$-lactam antibiotics were not considered for TDM because of their low toxicity and proven efficacy of empiric regimens. Nonetheless, in the current context of more heterogeneous patient populations with complex alterations in PK and the global burden of antibiotic resistance, TDM of $\beta$-lactam antibiotics is becoming more widespread [141, 144]. 


\subsubsection{Model-Informed Precision Dosing}

Model-informed precision dosing (MIPD) is an innovative approach that combines the knowledge from mathematical models describing the drug PK/PD behavior and individual TDM measurements to personalize antibiotic treatment. MIPD allows prescribers to determine the starting dose before any TDM sample is taken. When TDM measurements become available, MIPD will combine the information from the PK/PD model and individual patient PK characteristics to further personalize the dosing regimen during treatment [145-147]. The main advantages of this approach are that target concentrations can be achieved earlier in the course of the drug therapy when compared with classical TDM, and that it can predict future drug concentrations. Additionally, TDM samples do not have to be collected at steady state. Although MIPD sounds attractive as a strategy, there are several hurdles that hinder implementation on a large scale (e.g., software issues, training of personnel, the need for richly sampled prior PK data, selection of the appropriate model) [145, 146].

When reviewing the case of vancomycin, it is clear that abundant data on the PK in different populations and many population PK models have been published [148]. However, prospective studies investigating the clinical benefit of the application of MIPD are far less available. Limited data in neonates and critically ill adults have shown that MIPD improved the PK/PD target attainment of vancomycin [149, 150]. Application of MIPD for vancomycin in a pediatric teaching hospital, including patients admitted to the PICU, showed similar results [151].

\section{Optimal Route: Intravenous to Oral Switch Therapy}

The major concern of clinicians in making the intravenous to oral (IV-to-PO) switch of an antibiotic in the PICU is a fear for reduced bioavailability in oral versus intravenous formulations. However, for a large group of antibiotics it is proven that, if the circumstances are right, essentially the same amount of drug is found in the blood when given intravenously or orally [152]. The few studies that have investigated the bioequivalence, efficacy, and safety of an early IV-to-PO antibiotic switch in eligible adults ICU patients demonstrated a shorter ICU LOS, no increase in mortality, and lower costs of antibiotic therapy [153]. Nevertheless, we should remain cautious in critically ill patients, as was illustrated by anecdotal PK data on IV-to-PO switch of moxifloxacin in an adult ICU [154].

The Australasian Society for Infectious Diseases has issued evidence-based recommendations for optimal IV and total antibiotic duration and criteria for IV-to-PO switch for a number of specific pediatric infections [155]. They did not report on critical illness specifically, but based on their recommendations some general guidance for clinical decision making can be formulated (Table 2). Data on the outcome of early IV-to-PO switch of antibiotics in critically ill children are lacking.

In general, an early IV-to-PO antibiotic switch is an important AS intervention. Yet the question remains how applicable this intervention is in a PICU setting. This patient population is by definition not 'clinically stable' and is often at risk for impaired antibiotic absorption. Additionally, for certain severe infections no appropriate oral antibiotic exists (e.g., meningitis). However, in some cases an IV-to-PO switch is indeed possible in PICU patients and it should be a standard consideration while reviewing an individual patient's treatment regimen.

\section{Future Perspectives}

What seems to be an easy-to-achieve measure, 'the right drug in the right dose for the right duration', has been proven to be quite difficult to implement. As described above, rapid diagnostics have revolutionized diagnostic support.

Table 2 General principles guiding intravenous to oral switch of antibiotics (adapted from McMullan et al. [155])

Clinical condition

Clinically stable without signs of severe sepsis (fever alone need not prevent switch)

Ability to absorb oral antibiotics

Able to tolerate oral medication (not vomiting/nausea or nil per os)

No impairment to absorption (e.g., mucositis, altered gut motility)

Older than 28 days ( $<28$ days not an absolute contraindication, but absorption variable)

Availability of an appropriate oral antibiotic

Antibiotic treats the identified or expected organism

Antibiotic available in appropriate or palatable pediatric formulation

Antibiotic has sufficient penetration of affected tissues 
Correct interpretation of test results is challenging, however, and the specific benefits of biomarkers such as PCT and of rapid PCR assays in PICU patients need to be clarified further. In the PICU population, inflammation is not always related to infection. Sepsis-mimicking syndromes, such as hemophagocytic lymphohistiocytosis, macrophage activation syndrome, cytokine release syndrome, and autoimmune disorders, are increasingly recognized. It is crucial to discriminate between bacterial infection and these inflammatory syndromes, as the latter require different therapeutic approaches with immune modulatory therapy. New insights and research into new sets of biomarkers can be expected.

Research on common bacterial infectious emergencies should focus on duration of therapy, as this may be a key factor to decrease antibiotic pressure. The impact of interventions such as ADE on clinical outcome and on antibiotic resistance patterns needs to be clarified as well.

More research into 'right dosage' is required of antibiotics in critically ill children as dosage schedules may need a significant overhaul. In particular, knowledge on the impact of critical illness on antibiotic disposition at the site of infection (e.g., CSF, bronchial epithelial lining fluid) warrants further study. Instead of using fixed PK/ PD target values, more sophisticated models incorporating the full time-course of bacterial growth and killing are the next step in finetuning antibiotic PK/PD targets. Outcome data on morbidity and mortality of proposed strategies to optimize dosing are required as well, as an improved PK/ PD target attainment may not necessarily translate into a clinically and economically measurable benefit.

The majority of antibiotic prescriptions are made in district hospitals, where the resources and skills to invest in an ASP may be lacking. Most PICUs have an outreaching function; responsible antibiotic prescribing could be integrated into an outreach program by providing clinical guidelines and education. To achieve adequate training, however, insights into behavioral aspects of antibiotic prescribing should be further explored.

\section{Declarations}

Funding The Ph.D. research of Eline Hermans is supported by the Research Foundation Flanders (SB 1S38420N).

Conflicts of Interest The authors declare no conflicts of interest for this manuscript.

Ethics Approval Not applicable.

Consent to Participate Not applicable.

Consent for Publication Not applicable.

Availability of Data and Material Not applicable.
Code Availability Not applicable.

\section{References}

1. Shulman ST. The History of Pediatric Infectious Diseases. Pediatr Res. 2004;55:163-76.

2. Kelly CP, LaMont JT. Clostridium difficile-more difficult than ever. N Engl J Med. 2008;359:1932-40.

3. Gorkiewicz G, Moschen A. Gut microbiome: a new player in gastrointestinal disease. Virchows Arch. 2018;472:159-72.

4. Hersh AL, Gerber JS, Hicks LA, Pavia AT. Lessons learned in antibiotic stewardship: fluoroquinolone use in pediatrics. J Pediatric Infect Dis Soc. 2015;4(1):57-9.

5. Medernach RL, Logan LK. The growing threat of antibiotic resistance in children. Infect Dis Clin North Am. 2018;32:1-17.

6. Armand-Lefèvre L, Angebault C, Barbier F, Hamelet E, Defrance G, Ruppé E, et al. Emergence of imipenem-resistant gramnegative bacilli in intestinal flora of intensive care patients. Antimicrob Agents Chemother Antimicrob Agents Chemother. 2013;57:1488-95.

7. The Review on Antimicrobial Resistance, chaired by Jim O'Neill. Antimicrobial Resistance: Tackling a crisis for the health and wealth of nations. 2014. http://www.jpiamr.eu/wp-content/uploa ds/2014/12/AMR-Review-Paper-Tackling-a-crisis-for-the-healt h-and-wealth-of-nations_1-2.pdf.

8. World Health Organization. Global action plan on antimicrobial resistance. World Health Organization. 2015. https://apps.who. int/iris/bitstream/handle/10665/193736/9789241509763_eng. pdf? sequence $=1 \&$ isAllowed $=y$.

9. Bizzarro MJ, Gallagher PG. Antibiotic-resistant organisms in the neonatal intensive care unit. Semin Perinatol. 2007;31:26-32.

10. Blaschke AJ, Korgenski EK, Daly JA, LaFleur B, Pavia AT, Byington CL. Extended-spectrum $\beta$-lactamase-producing pathogens in a children's hospital: a 5-year experience. Am J Infect Control. 2009;37:435-41.

11. Benner KW, Prabhakaran P, Lowros AS. Epidemiology of infections due to extended-spectrum beta-lactamase-producing bacteria in a pediatric intensive care unit. J Pediatr Pharmacol Ther. 2014;19:83-90.

12. Huang Y-C, Su L-H, Wu T-L, Leu H-S, Hsieh W-S, Chang T-M, et al. Outbreak of Acinetobacter baumannii bacteremia in a neonatal intensive care unit: clinical implications and genotyping analysis. Pediatr Infect Dis J. 2002;21:1105-9.

13. Logan LK, Gandra S, Mandal S, Klein EY, Levinson J, Weinstein RA, et al. Multidrug- and carbapenem-resistant Pseudomonas aeruginosa in Children, United States, 1999-2012. J Pediatric Infect Dis Soc. 2017;6:352-9.

14. Herold BC, Immergluck LC, Maranan MC, Lauderdale DS, Gaskin RE, Boyle-Vavra S, et al. Community-acquired methicillin-resistant Staphylococcus aureus in children with no identified predisposing risk. JAMA. 1998;279:593-8.

15. Sutter DE, Milburn E, Chukwuma U, Dzialowy N, Maranich AM, Hospenthal DR. Changing susceptibility of Staphylococcus aureus in a US pediatric population. Pediatrics. 2016;137:e20153099-e20153099.n

16. Versporten A, Sharland M, Bielicki J, Drapier N, Vankerckhoven $\mathrm{V}$, Goossens $\mathrm{H}$. The antibiotic resistance and prescribing in European Children project: a neonatal and pediatric antimicrobial web-based point prevalence survey in 73 hospitals worldwide. Pediatr Infect Dis J. 2013;32(6):e242-53.

17. Dellit TH, Owens RC, McGowan JE, Gerding DN, Weinstein RA, Burke JP, et al. Infectious Diseases Society of America and the Society for Healthcare Epidemiology of America Guidelines 
for Developing an Institutional Program to Enhance Antimicrobial Stewardship. Clin Infect Dis. 2007;44:159-77.nn

18. Blinova E, Lau E, Bitnun A, Cox P, Schwartz S, Atenafu E, et al. Point prevalence survey of antimicrobial utilization in the cardiac and pediatric critical care unit. Pediatr Crit Care Med. 2013; 14:e280-8.nn

19. Gerding DN. The search for good antimicrobial stewardship. Jt Comm J Qual Improv. 2001;27:403-4.nn

20. Craig JC, Williams GJ, Jones M, Codarini M, Macaskill P, Hayen A, et al. The accuracy of clinical symptoms and signs for the diagnosis of serious bacterial infection in young febrile children: prospective cohort study of 15781 febrile illnesses. BMJ. 2010;340:1015.

21. Weiss SL, Fitzgerald JC, Balamuth F, Alpern ER, Lavelle J, Chilutti M, et al. Delayed antimicrobial therapy increases mortality and organ dysfunction duration in pediatric sepsis. Crit Care Med. 2014;42:2409-17.nn

22. Nadel S, Britto J, Booy R, Maconochie I, Habibi P, Levin M. Avoidable deficiencies in the delivery of health care to children with meningococcal disease. Emerg Med J. 1998;15:298-303.nn

23. Zilahi G, McMahon MA, Povoa P, Martin-Loeches I. Duration of antibiotic therapy in the intensive care unit. J Thorac Dis. 2016;8(12):3774-80.

24. Fontela PS, Quach C, Karim ME, Willson DF, Gilfoyle E, McNally JD, et al. Determinants of Antibiotic Tailoring in Pediatric Intensive Care: A National Survey*. Pediatr Crit Care Med. 2017;18:e395-405.nn

25. Raissy HH, Blake K. Macrolides for acute wheezing episodes in preschool children. Pediatr Allergy Immunol Pulmonol. 2016;29:100-3.nn

26. Levine DA, Platt SL, Dayan PS, Macias CG, Zorc JJ, Krief $\mathrm{W}$, et al. Risk of serious bacterial infection in young febrile infants with respiratory syncytial virus infections. Pediatrics. 2004;113:1728-34.nn

27. Krüger S, Welte T. Biomarkers in community-acquired pneumonia. Expert Rev Respir Med. 2012;6(2):203-14.

28. de Jong E, van Oers JA, Beishuizen A, Vos P, Vermeijden WJ, Haas LE, et al. Efficacy and safety of procalcitonin guidance in reducing the duration of antibiotic treatment in critically ill patients: a randomised, controlled, open-label trial. Lancet Infect Dis. 2016;16:819-27.nn

29. Gomez B, Mintegi S, Bressan S, Da Dalt L, Gervaix A, Lacroix L. Validation of the "step-by-step" approach in the management of young febrile infants. Pediatrics. 2016;138(2):e20154381. https://doi.org/10.1542/peds.2015-4381.

30. Mandell IM, Aghamohammadi S, Deakers T, Khemani RG. Procalcitonin to detect suspected bacterial infections in the PICU. Pediatr Crit Care Med. 2016;17:e4-12.n

31. D'Souza S, Guhadasan R, Jennings R, Siner S, Paulus S, Thorburn K, et al. Procalcitonin and other common biomarkers do not reliably identify patients at risk for bacterial infection after congenital heart surgery. Pediatr Crit Care Med. 2019;20:243-51.nn

32. Van De Pol AC, Wolfs TFW, Tacke CEA, Uiterwaal CSP, Forster J, Van Loon AM, et al. Impact of PCR for respiratory viruses on antibiotic use: theory and practice. Pediatr Pulmonol. 2011;46:428-34.nn

33. Rogers BB, Shankar P, Jerris RC, Kotzbauer D, Anderson EJ, Watson JR, et al. Impact of a rapid respiratory panel test on patient outcomes. Arch Pathol Lab Med. 2015;139:636-41.n

34. Messacar K, Hurst AL, Child J, Campbell K, Palmer C, Hamilton $\mathrm{S}$, et al. Clinical impact and provider acceptability of real-time antimicrobial Stewardship Decision Support for Rapid Diagnostics in Children with positive blood culture results. J Pediatric Infect Dis Soc. 2017;6:267-74.nnn

35. Blaschke AJ, Heyrend C, Byington CL, Fisher MA, Barker E, Garrone NF, et al. Rapid identification of pathogens from positive blood cultures by multiplex polymerase chain reaction using the FilmArray system. Diagn Microbiol Infect Dis. 2012;74:349-55.nn

36. Leber AL, Everhart K, Balada-Llasat J-M, Cullison J, Daly $\mathrm{J}$, Holt S, et al. Multicenter evaluation of BioFire FilmArray meningitis/encephalitis panel for detection of bacteria, viruses, and yeast in cerebrospinal fluid specimens. J Clin Microbiol. 2016;54:2251-61 ((Forbes BA, editor)).nn

37. Banerjee R, Teng CB, Cunningham SA, et al. Randomized trial of rapid multiplex polymerase chain reaction-based blood culture identification and susceptibility testing. Clin Infect Dis. 2015;61:1071-80.nn

38. Felsenstein S, Bender JM, Sposto R, Gentry M, Takemoto C, Bard JD. Impact of a rapid blood culture assay for gram-positive identification and detection of resistance markers in a pediatric hospital. Arch Pathol Lab Med. 2016;140:267-75.nn

39. Messacar K, Parker SK, Todd JK, Dominguez SR. Implementation of rapid molecular infectious disease diagnostics: the role of diagnostic and antimicrobial stewardship. J Clin Microbiol. 2017;55:715-23.nn

40. Livermore DM, Wain J. Revolutionising bacteriology to improve treatment outcomes and antibiotic stewardship. Infect Chemother. 2013;45(1):1-10.

41. Rhodes A, Evans LE, Alhazzani W, Levy MM, Antonelli M, Ferrer R, et al. Surviving sepsis campaign: international guidelines for management of sepsis and septic shock: 2016. Intensive Care Med. 2017;43:304-77.nn

42. Tunkel AR, Hartman BJ, Kaplan SL, Kaufman BA, Roos KL, Scheld WM, et al. Practice guidelines for the management of bacterial meningitis. Clin Infect Dis. 2004;39:1267-84.nn

43. Le Saux N, Robinson J. Pneumonia in healthy Canadian children and youth: practice points for management. Paediatr Child Health. 2011;16(7):417-24.

44. Solomkin JS, Mazuski JE, Bradley JS, et al. Diagnosis and management of complicated intra-abdominal infection in adults and children: guidelines by the Surgical Infection Society and the Infectious Diseases Society of America. Clin Infect Dis. 2010;50:133-64.nn

45. De Bus L, Saerens L, Gadeyne B, Boelens J, Claeys G, De Waele $\mathrm{JJ}$, et al. Development of antibiotic treatment algorithms based on local ecology and respiratory surveillance cultures to restrict the use of broad-spectrum antimicrobial drugs in the treatment of hospital-acquired pneumonia in the intensive care unit: a retrospecti. Crit Care. 2014;18:R152.n

46. Tabah A, Cotta MO, Garnacho-Montero J. A systematic review of the definitions, determinants, and clinical outcomes of antimicrobial de-escalation in the Intensive Care Unit. Clin Infect Dis. 2016;62:1009-17.nn

47. De Bus L, Depuydt P, Steen J, Dhaese S, De Smet K, Tabah A, et al. Antimicrobial de-escalation in the critically ill patient and assessment of clinical cure: the DIANA study. Jose Garnacho Montero. 2020;8:29.nn

48. De Bus L, Denys W, Catteeuw J, Gadeyne B, Vermeulen K, Boelens J, et al. Impact of de-escalation of beta-lactam antibiotics on the emergence of antibiotic resistance in ICU patients: a retrospective observational study. Intensive Care Med. 2016;42:102939.nn

49. Henderson KL, Müller-Pebody B, Johnson AP, Wade A, Sharland M, Gilbert R. Community-acquired, healthcare-associated and hospital-acquired bloodstream infection definitions in children: a systematic review demonstrating inconsistent criteria. J Hosp Infect. 2013:94-105.

50. Gauvin F, Dassa C, Chaïbou M, Proulx F, Farrell CA, Lacroix J. Ventilator-associated pneumonia in intubated children: comparison of different diagnostic methods. Pediatr Crit Care Med. 2003;4:437-43.nn 
51. Cantey JB, Lopez-Medina E, Nguyen S, Doern C, Garcia C. Empiric Antibiotics for Serious bacterial infection in young infants: opportunities for Stewardship. Pediatr Emerg Care. 2015;31:568-71.nn

52. Schaad UB, Suter S, Gianella-Borradori A, Pfenninger J, Auckenthaler R, Bernath O, et al. A comparison of ceftriaxone and cefuroxime for the treatment of bacterial meningitis in children. N Engl J Med. 1990;322:141-7.nn

53. Ahmed A. A critical evaluation of vancomycin for treatment of bacterial meningitis. Pediatr Infect Dis J. 1997;16(9):895-903.

54. Carapetis JR, Jacoby P, Carville K, Ang S-JJ, Curtis N, Andrews $\mathrm{R}$. Effectiveness of clindamycin and intravenous immunoglobulin, and risk of disease in contacts, in invasive group a streptococcal infections. Clin Infect Dis. 2014;59:358-65.

55. Nair H, Simões EAF, Rudan I, Gessner BD, Azziz-Baumgartner E, Zhang JSF, et al. Global and regional burden of hospital admissions for severe acute lower respiratory infections in young children in 2010: a systematic analysis. Lancet. 2013;381:138090.nn

56. Jiang W, Wu M, Zhou J, Wang Y, Hao C, Ji W, et al. Etiologic spectrum and occurrence of coinfections in children hospitalized with community-acquired pneumonia. BMC Infect Dis. 2017;17(1):787.

57. Muszynski JA, Knatz NL, Sargel CL, Fernandez SA, Marquardt DJ, Hall MW. Timing of correct parenteral antibiotic initiation and outcomes from severe bacterial community-acquired pneumonia in children. Pediatr Infect Dis J. 2011;30:295-301.nn

58. Harris M, Clark J, Coote N, Fletcher P, Harnden A, McKean M, et al. British Thoracic Society guidelines for the management of community acquired pneumonia in children: update 2011. Thorax [Internet]. 2011;66:ii1 LP-ii23. https://thorax.bmj.com/conte nt/66/Suppl_2/ii1.abstract

59. Harris JAS, Kolokathis A, Campbell M, Cassell GH, Hammerschlag MR. Safety and efficacy of azithromycin in the treatment of community-acquired pneumonia in children. Pediatr Infect Dis J. 1998;17:865-71.nn

60. Klein M. Multicenter trial of cefpodoxime proxetil vs. amoxicillin-clavulanate in acute lower respiratory tract infections in childhood. Pediatr Infect Dis J. 1995;14:19-22.

61. Biondi E, McCulloh R, Alverson B, Klein A, Dixon A, Ralston $\mathrm{S}$. Treatment of mycoplasma pneumonia: a systematic review. Pediatrics. 2014;133(6):1081-90.

62. Grohskopf LA, Sinkowitz-Cochran RL, Garrett DO, Sohn AH, Levine GL, Siegel JD, et al. A national point-prevalence survey of pediatric intensive care unit-acquired infections in the United States. J Pediatr. 2002;140:432-8.nn

63. Alten JA, Rahman AKMF, Zaccagni HJ, Shin A, Cooper DS, Blinder JJ, et al. The Epidemiology of Healthcare-associated Infections in Pediatric Cardiac Intensive Care Units. Pediatr Infect Dis J. 2018;37:768-72.nn

64. Sievert DM, Ricks P, Edwards JR, Schneider A, Patel J, Srinivasan A, et al. Antimicrobial-resistant pathogens associated with healthcare-associated infections summary of data reported to the national healthcare safety network at the Centers for Disease Control and Prevention, 2009-2010. Infect Control Hosp Epidemiol. 2013;34:1-14.nn

65. Niedner MF, Huskins WC, Colantuoni E, Muschelli J, Harris JM, Rice TB, et al. Epidemiology of central line-associated bloodstream infections in the pediatric intensive care unit. Infect Control Hosp Epidemiol. 2011;32:1200-8.nn

66. Goudie A, Dynan L, Brady PW, Rettiganti M. Attributable cost and length of stay for central line-associated bloodstream infections. Pediatrics. 2014;133.

67. Elward AM, Hollenbeak CS, Warren DK, Fraser VJ. Attributable cost of nosocomial primary bloodstream infection in pediatric intensive care unit patients. Pediatrics. 2005;115:868-72.nn

68. Patrick SW, Kawai AT, Kleinman K, Jin R, Vaz L, Gay C, et al. Health care-associated infections among critically ill children in the US, 2007-2012. Pediatrics. 2014;134:705-12.nn

69. Lake JG, Weiner LM, Milstone AM, Saiman L, Magill SS, See I. Pathogen distribution and antimicrobial resistance among pediatric healthcare-associated infections reported to the National Healthcare Safety Network, 2011-2014. Infect Control Hosp Epidemiol. 2018;39:1-11.nn

70. Mermel LA, Allon M, Bouza E, et al. Clinical practice guidelines for the diagnosis and management of intravascular catheterrelated infection: 2009 Update by the Infectious Diseases Society of America. Clin Infect Dis. 2009;49:1-45.nn

71. Fischer JE, Ramser M, Fanconi S. Use of antibiotics in pediatric intensive care and potential savings. Intensive Care Med. 2000;26:959-66.n

72. Patria MF, Chidini G, Ughi L, Montani C, Prandi E, Galeone $\mathrm{C}$, et al. Ventilator-associated pneumonia in an Italian pediatric intensive care unit: a prospective study. World J Pediatr. 2013;9:365-8.nnn

73. Elward AM. Pediatric ventilator-associated pneumonia. Pediatr Infect Dis J. 2003;22:445-6.nn

74. Klompas M, Magill S, Robicsek A, Strymish JM, Kleinman $\mathrm{K}$, Evans RS, et al. Objective surveillance definitions for ventilator-associated pneumonia. Crit Care Med Crit Care Med. 2012;40:3154-61.nn

75. Willson DF, Conaway M, Kelly R, Hendley JO. The lack of specificity of tracheal aspirates in the diagnosis of pulmonary infection in intubated children. Pediatr Crit Care Med. 2014;15:299305.nn

76. Renk H, Stoll L, Neunhoeffer F, Hölzl F, Kumpf M, Hofbeck $\mathrm{M}$, et al. Suspicion of respiratory tract infection with multidrug-resistant Enterobacteriaceae: epidemiology and risk factors from a Paediatric Intensive Care Unit. BMC Infect Dis. 2017;17(1):163.

77. Luna CM, Sarquis S, Niederman MS, Sosa FA, Otaola M, Bailleau $\mathrm{N}$, et al. Is a strategy based on routine endotracheal cultures the best way to prescribe antibiotics in ventilator-associated pneumonia ? Chest. 2013;144:63-71.nn

78. Iregui M, Ward S, Sherman G, Fraser VJ, Kollef MH. Clinical importance of delays in the initiation of appropriate antibiotic treatment for ventilator-associated pneumonia. Chest. 2002;122:262-8.nn

79. Kollef MH, Shorr A, Tabak YP, Gupta V, Liu LZ, Johannes RS. Epidemiology and outcomes of health-care-associated pneumonia: results from a large US database of culture-positive pneumonia. Chest. 2005;128:3854-62.n

80. Weber DJ, Rutala WA, Sickbert-Bennett EE, Samsa GP, Brown V, Niederman MS. Microbiology of ventilator-associated pneumonia compared with that of hospital-acquired pneumonia. Infect Control Hosp Epidemiol. 2007;28:825-31.nn

81. Niederman MS. Antibiotic treatment of hospital-acquired pneumonia: is it different from ventilator-associated pneumonia? Curr Opin Crit Care. 2018;24(5):353-60.

82. Teshome BF, Vouri SM, Hampton N, Kollef MH, Micek ST. Duration of exposure to antipseudomonal $\beta$-lactam antibiotics in the critically Ill and development of new resistance. Pharmacotherapy. 2019;39:261-70.nn

83. Llewelyn MJ, Fitzpatrick JM, Darwin E, Gorton C, Paul J, et al. The antibiotic course has had its day. BMJ. 2017;358:j3418.

84. Warrick C, Naik H, Avis S, Fletcher P, Franklin BD, Inwald D. A clinical information system reduces medication errors in paediatric intensive care. Intensive Care Med. 2011;37:691-4.nn 
85. Ross RK, Beus JM, Metjian TA, Localio AR, Shelov ED, Desai BR, et al. Safety of automatic end dates for antimicrobial orders to Facilitate Stewardship. Infect Control Hosp Epidemiol. 2016;37:974-8.nn

86. Molyneux E, Nizami SQ, Saha S, Huu KT, Azam M, Bhutta ZA, et al. 5 versus 10 days of treatment with ceftriaxone for bacterial meningitis in children: a double-blind randomised equivalence study. Lancet. 2011;377:1837-45.nn

87. Esposito S, Cohen R, Domingo JD, Pecurariu OF, Greenberg D, Heininger U, et al. Antibiotic therapy for pediatric communityacquired pneumonia: do we know when, what and for how long to treat? Pediatr Infect Dis J. 2012;31(6):e78-85.

88. Lassi ZS, Imdad A, Bhutta ZA. Short-course versus long-course intravenous therapy with the same antibiotic for severe community-acquired pneumonia in children aged two months to 59 months. Cochrane Database Syst Rev. 2017;10(10):Cd008032.

89. Chesshyre E, Goff Z, Bowen A, Carapetis J. The prevention, diagnosis and management of central venous line infections in children. J Infect. 2015;71:S59-75.nn

90. Rijnders BJ, Van Wijngaerden E, Vandecasteele SJ, Stas MPW. Treatment of long-term intravascular catheter-related bacteraemia with antibiotic lock: randomized, placebo-controlled trial. J Antimicrob Chemother. 2005;55:90-4.nn

91. Chastre J, Wolff M, Fagon JY, Chevret S, Thomas F, Wermert D, et al. Comparison of 8 vs 15 days of antibiotic therapy for ventilator-associated pneumonia in adults: a randomized trial. $\mathrm{J}$ Am Med Assoc. 2003;290:2588-98.n

92. Chang I, Schibler A. Ventilator associated pneumonia in children. Paediatr Respir Rev. 2016;20:10-6.

93. Czaja AS, Reiter PD, Schultz ML, Valuck RJ. Patterns of offlabel prescribing in the pediatric intensive care unit and prioritizing future research. J Pediatr Pharmacol Ther. 2015;20:186-96 (2015/07/15)

94. Batchelor HK, Marriott JF. Paediatric pharmacokinetics: key considerations. Br J Clin Pharmacol [Internet]. 2015;79:395-404. https://www.ncbi.nlm.nih.gov/pubmed/25855821 (2015/04/10).

95. Dorofaeff T, Bandini RM, Lipman J, Ballot DE, Roberts JA, Parker SL. Uncertainty in antibiotic dosing in critically ill neonate and pediatric patients: Can microsampling provide the answers? Clin Ther [Internet]. 2016;38:1961-75. https://www. ncbi.nlm.nih.gov/pubmed/27544661 (2016/08/22).

96. Hartman S, Schreuder M, De Wildt SN. Pharmacokinetics of antibiotics in critically Ill children: a systematic review of current literature. Clin Pharmacol Ther. 2019;105:S98-S98.nn

97. Cies JJ, Moore WS, Enache A, Chopra A. $\beta$-lactam therapeutic drug management in the PICU. Crit Care Med. 2018;46:272-9. $\mathrm{nn}$

98. van Donge T, Bielicki JA, van den Anker J, Pfister M. Key components for antibiotic dose optimization of sepsis in neonates and infants. Front Pediatr [Internet]. 2018;6:325. https://www.ncbi. nlm.nih.gov/pubmed/30420947 (2018/11/14).

99. van den Anker JN, Schwab M, Kearns GL. Developmental pharmacokinetics. Handb Exp Pharmacol [Internet]. 2011;205:51-75. https://www.ncbi.nlm.nih.gov/pubmed/21882105 (2011/09/02).

100. De Cock P. Impact of critical illness and cardiopulmonary bypass on antibiotic disposition in children. Ghent, Belgium: Ghent University, Faculty of Medicine and Health Sciences; 2017.

101. Roberts JA, Lipman J. Pharmacokinetic issues for antibiotics in the critically ill patient. Crit Care Med [Internet]. 2009;37:84051; quiz 859. https://www.ncbi.nlm.nih.gov/pubmed/19237886 $(2009 / 02 / 25)$

102. Roberts JA, Roberts MS, Semark A, Udy AA, Kirkpatrick CM, Paterson DL, et al. Antibiotic dosing in the "at risk" critically ill patient: Linking pathophysiology with pharmacokinetics/pharmacodynamics in sepsis and trauma patients. BMC Anesthesiol
[Internet]. 2011;11:3. https://www.ncbi.nlm.nih.gov/pubme $\mathrm{d} / 21333028$ (2011/02/22).

103. Zuppa AF, Barrett JS. Pharmacokinetics and pharmacodynamics in the critically ill child. Pediatr Clin North Am [Internet] 2008;55:735-55, xii. https://www.ncbi.nlm.nih.gov/pubme $\mathrm{d} / 18501763$ (2008/05/27).

104. Shah S, Barton G, Fischer A. Pharmacokinetic considerations and dosing strategies of antibiotics in the critically ill patient. J Intensive Care Soc [Internet]. 2015;16:147-53. https://www. ncbi.nlm.nih.gov/pubmed/28979397 (2015/05/01).

105. Lopez-Herce J, Mencia S, Sanchez C, Santiago MJ, Bustinza A, Vigil D. Postpyloric enteral nutrition in the critically ill child with shock: a prospective observational study. Nutr J [Internet]. 2008;7:6. https://www.ncbi.nlm.nih.gov/pubmed/18237381 $\mathbf{( 2 0 0 8 / 0 2 / 0 2 )}$

106. Woolsey CA, Coopersmith CM. Vasoactive drugs and the gut: is there anything new? Curr Opin Crit Care. 2006;12:155-9 (2006/03/18).

107. Moseley RH. Sepsis and cholestasis. Clin Liver Dis [Internet]. 2004;8:83-94. https://www.ncbi.nlm.nih.gov/pubmed/15062195 (2004/04/06).

108. Bhamidimarri KR, Schiff E. Drug-induced cholestasis. Clin Liver Dis [Internet]. 2013;17:519-31, vii. https://www.ncbi.nlm.nih. gov/pubmed/24099015 (2013/10/09).

109. Leroy S, Isapof A, Fargue S, Fakhoury M, Bensman A, Deschenes G, et al. Tacrolimus nephrotoxicity: beware of the association of diarrhea, drug interaction and pharmacogenetics. Pediatr Nephrol [Internet]. 2010;25:965-9. https://www.ncbi. nlm.nih.gov/pubmed/20091056 (2010/01/22).

110. Roberts JA, Abdul-Aziz MH, Lipman J, Mouton JW, Vinks AA, Felton TW, et al. Individualised antibiotic dosing for patients who are critically ill: challenges and potential solutions. Lancet Infect Dis [Internet]. 2014;14:498-509. https://www.ncbi.nlm. nih.gov/pubmed/24768475 (2014/04/29).

111. Horowitz IN, Tai K. Hypoalbuminemia in critically ill children. Arch Pediatr Adolesc Med. 2007;161:1048-52.n

112. Thakkar N, Salerno S, Hornik CP, Gonzalez D. Clinical Pharmacology Studies in Critically Ill Children. Pharm Res [Internet]. 2017;34:7-24. https://www.ncbi.nlm.nih.gov/pubmed/27585904 (2016/09/03)

113. Joukhadar C, Frossard M, Mayer BX, Brunner M, Klein N, Siostrzonek P, et al. Impaired target site penetration of beta-lactams may account for therapeutic failure in patients with septic shock. Crit Care Med [Internet]. 2001;29:385-91. https://www. ncbi.nlm.nih.gov/pubmed/11246321 (2001/03/14).

114. Roberts JA, Roberts MS, Robertson TA, Dalley AJ, Lipman J. Piperacillin penetration into tissue of critically ill patients with sepsis--bolus versus continuous administration? Crit Care Med [Internet]. 2009;37:926-33. https://www.ncbi.nlm.nih.gov/ pubmed/19237898 (2009/02/25).

115. Sauermann R, Delle-Karth G, Marsik C, Steiner I, Zeitlinger M, Mayer-Helm BX, et al. Pharmacokinetics and pharmacodynamics of cefpirome in subcutaneous adipose tissue of septic patients. Antimicrob Agents Chemother [Internet]. 2005;49:650-5. https ://www.ncbi.nlm.nih.gov/pubmed/15673747 (2005/01/28).

116. Vet NJ, de Hoog M, Tibboel D, de Wildt SN. The effect of inflammation on drug metabolism: a focus on pediatrics. Drug Discov Today. 2011;16:435-42 (2011/03/08).

117. Dhont E, Van Der Heggen T, De Jaeger A, Vande Walle J, De Paepe P, De Cock PA. Augmented renal clearance in pediatric intensive care: are we undertreating our sickest patients? Pediatr Nephrol. 2020;35:25-39 (2018/10/31).

118. Perkins MW, Dasta JF, DeHaven B. Physiologic implications of mechanical ventilation on pharmacokinetics. DICP. 1989;23:316-23 (1989/04/01). 
119. Ha MA, Sieg AC. Evaluation of altered drug pharmacokinetics in critically Ill adults receiving extracorporeal membrane oxygenation. Pharmacotherapy [Internet]. 2017;37:221-35. https://www. ncbi.nlm.nih.gov/pubmed/27931091 (2016/12/09).

120. Himebauch AS, Kilbaugh TJ, Zuppa AF. Pharmacotherapy during pediatric extracorporeal membrane oxygenation: a review. Expert Opin Drug Metab Toxicol. 2016;12:1133-42.nn

121. Raffaeli G, Pokorna P, Allegaert K, Mosca F, Cavallaro G, Wildschut ED, et al. Drug Disposition and pharmacotherapy in neonatal ECMO: from fragmented data to integrated knowledge. Front Pediatr [Internet]. 2019;7:360. https://www.ncbi.nlm.nih. gov/pubmed/31552205 (2019/09/26).

122. Sherwin J, Heath T, Watt K. Pharmacokinetics and dosing of anti-infective drugs in patients on extracorporeal membrane oxygenation: a review of the current literature. Clin Ther [Internet]. 2016;38:1976-94. https://www.ncbi.nlm.nih.gov/pubmed/27553 752 (2016/08/25).

123. Mulla H, Pooboni S. Population pharmacokinetics of vancomycin in patients receiving extracorporeal membrane oxygenation. $\mathrm{Br}$ J Clin Pharmacol [Internet]. 2005;60:265-75. https://www.ncbi. nlm.nih.gov/pubmed/16120065 (2005/08/27).

124. Hoff BM, Maker JH, Dager WE, Heintz BH. Antibiotic dosing for critically Ill adult patients receiving intermittent hemodialysis, prolonged intermittent renal replacement therapy, and continuous renal replacement therapy: an update. Ann Pharmacother [Internet]. 2020;54:43-55. https://journals.sagepub.com/ doi/pdf/10.1177/1060028019865873 (2019/07/26).

125. Nehus EJ, Mizuno T, Cox S, Goldstein SL, Vinks AA. Pharmacokinetics of meropenem in children receiving continuous renal replacement therapy: validation of clinical trial simulations. J Clin Pharmacol [Internet]. 2016;56:291-7. https://accp1.onlin elibrary.wiley.com/doi/full/10.1002/jcph.601 (2015/07/30).

126. Lee B, Kim SJ, Park JD, Park J, Jung AH, Jung SH, et al. Factors affecting serum concentration of vancomycin in critically ill oliguric pediatric patients receiving continuous venovenous hemodiafiltration. PLoS One [Internet]. 2018;13:e0199158. https://www.ncbi.nlm.nih.gov/pmc/articles/PMC6013195/pdf/ pone.0199158.pdf (2018/06/22).

127. Nielsen EI, Friberg LE. Pharmacokinetic-pharmacodynamic modeling of antibacterial drugs. Pharmacol Rev [Internet]. 2013;65:1053-90. https://pharmrev.aspetjournals.org/content/ pharmrev/65/3/1053.full.pdf (2013/06/28).

128. De Waele JJ, Lipman J, Akova M, Bassetti M, Dimopoulos G, Kaukonen M, et al. Risk factors for target non-attainment during empirical treatment with beta-lactam antibiotics in critically ill patients. Intensive Care Med. 2014;40:1340-51.nn

129. Béranger A, Benaboud S, Urien S, Moulin F, Bille E, Lesage F, et al. Piperacillin population pharmacokinetics and dosing regimen optimization in critically ill children with normal and augmented renal clearance. Clin Pharmacokinet. 2019;58:223-33. $\mathrm{nn}$

130. Cies JJ, Shankar V, Schlichting C, Kuti JL. Population pharmacokinetics of piperacillin/tazobactam in critically ill young children. Pediatr Infect Dis J. 2014;33:168-73.nn

131. De Cock PAJG, van Dijkman SC, de Jaeger A, Willems J, Carlier M, Verstraete AG, et al. Dose optimization of piperacillin/ tazobactam in critically ill children. J Antimicrob Chemother. 2017;72:2002-11.nn

132. Nichols K, Chung EK, Knoderer CA, Buenger LE, Healy DP, Dees J, et al. Population pharmacokinetics and pharmacodynamics of extended-infusion piperacillin and tazobactam in critically ill children. Antimicrob Agents Chemother. 2016;60:522-31.nn

133. Gwee A, Cranswick N, McMullan B, Perkins E, Bolisetty S, Gardiner K, et al. Continuous versus intermittent vancomycin infusions in infants: a randomized controlled trial. Pediatrics. 2019; 143 (2019/02/01).
134. McKamy S, Chen T, Lee M, Ambrose PJ. Evaluation of a pediatric continuous-infusion vancomycin therapy guideline. Am J Health Syst Pharm. 2012;69:2066-71 (2012/11/23).

135. De Waele JJ, Lipman J, Carlier M, Roberts JA. Subtleties in practical application of prolonged infusion of beta-lactam antibiotics. Int J Antimicrob Agents. 2015;45:461-3 (2015/03/10).

136. Rhodes NJ, MacVane SH, Kuti JL, Scheetz MH. Impact of loading doses on the time to adequate predicted beta-lactam concentrations in prolonged and continuous infusion dosing schemes. Clin Infect Dis [Internet]. 2014;59:905-7. https://watermark.silve rchair.com/ciu402.pdf?token=AQECAHi208BE49Ooan9kkhW_ Ercy7Dm3ZL_9Cf3qfKAc485ysgAAAmYwggJiBgkqhkiG9w 0BBwagggJTMIICTwIBADCCAkgGCSqGSIb3DQEHATAeBgl ghkgBZQMEAS4wEQQMq8P2mAZdEb_2xjMgAgEQgIICGa HAsUswRDJLQibOq8J9-Menr0cvogOneWg22chT9HHQ-V7c (2014/05/29).

137. Claus B, Buyle F, Robays H, Vogelaers D. Importance of infusion volume and pump characteristics in extended administration of ss-lactam antibiotics. Antimicrob Agents Chemother [Internet]. 2010;54:4950. https://www.ncbi.nlm.nih.gov/pubmed/20823285 (2010/09/09).

138. Shiu J, Wang E, Tejani AM, Wasdell M. Continuous versus intermittent infusions of antibiotics for the treatment of severe acute infections. Cochrane Database Syst Rev. 2013;3:Cd008481.

139. Drennan PG, Begg EJ, Gardiner SJ, Kirkpatrick CMJ, Chambers ST. The dosing and monitoring of vancomycin: what is the best way forward? Int J Antimicrob Agents [Internet]. 2019;53:401-7. https://pdf.sciencedirectassets.com/271247/1-s2.0-S092485791 9X00047/1-s2.0-S0924857918303844/main.pdf?X-Amz-Secur ity-Token=IQoJb3JpZ2luX2 VjEBoaCXVzLWVhc3QtMSJ HMEUCIHwerCWeJ1AQLj3xJ2IGSx 930CicZ1f7Us5yIrZ6 Nxy\%2FAiEAwhNpIjeeVlUxQmvoIgUdJYgAxRG5qruxZ4 tVrZmfpu (2019/01/02).

140. Jager NGL, van Hest RM, Lipman J, Taccone FS, Roberts JA. Therapeutic drug monitoring of anti-infective agents in critically ill patients. Expert Rev Clin Pharmacol. 2016;9:961-79.nn

141. Muller AE, Huttner B, Huttner A. Therapeutic drug monitoring of beta-lactams and other antibiotics in the intensive care unit: which agents, which patients and which infections? Drugs [Internet]. 2018;78:439-51. https://www.ncbi.nlm.nih.gov/pubme d/29476349 (2018/02/25)

142. Pea F, Furlanut M, Cojutti P, Cristini F, Zamparini E, Franceschi $\mathrm{L}$, et al. Therapeutic drug monitoring of linezolid: a retrospective monocentric analysis. Antimicrob Agents Chemother [Internet]. 2010;54:4605-10. https://www.ncbi.nlm.nih.gov/pmc/articles/ PMC2976143/pdf/0177-10.pdf (2010/08/25).

143. Pea F, Poz D, Viale P, Pavan F, Furlanut M. Which reliable pharmacodynamic breakpoint should be advised for ciprofloxacin monotherapy in the hospital setting? A TDM-based retrospective perspective. J Antimicrob Chemother. 2006;58:380-6 (2006/06/01).

144. Huttner A, Harbarth S, Hope WW, Lipman J, Roberts JA. Therapeutic drug monitoring of the beta-lactam antibiotics: what is the evidence and which patients should we be using it for? J Antimicrob Chemother [Internet]. 2015;70:3178-83. https://www.ncbi. nlm.nih.gov/pubmed/26188037 (2015/07/19).

145. Donagher J, Martin JH, Barras MA. Individualised medicine: why we need Bayesian dosing. Intern Med J [Internet]. 2017;47:593-600. https://onlinelibrary.wiley.com/doi/ full/10.1111/imj.13412 (2017/05/16).

146. Al-Metwali B, Mulla $\mathrm{H}$. Personalised dosing of medicines for children. J Pharm Pharmacol. 2017;69:514-24 (2017/03/08).

147. Avent ML, Rogers BA. Optimising antimicrobial therapy through the use of Bayesian dosing programs. Int J Clin Pharm. 2019;41:1121-30 (2019/08/09). 
148. Allegaert K, Flint R, Smits A. Pharmacokinetic modelling and Bayesian estimation-assisted decision tools to optimize vancomycin dosage in neonates: only one piece of the puzzle. Expert Opin Drug Metab Toxicol [Internet]. 2019;15:735-49. https:// www.tandfonline.com/doi/full/10.1080/17425255.2019.16555 $40(\mathbf{2 0 1 9 / 0 8 / 1 4 )}$.

149. Crumby T, Rinehart E, Carby MC, Kuhl D, Talati AJ. Pharmacokinetic comparison of nomogram-based and individualized vancomycin regimens in neonates. Am J Heal Syst Pharm. 2009;66:149-53 (2009/01/14).

150. Pea F, Bertolissi M, Di Silvestre A, Poz D, Giordano F, Furlanut M. TDM coupled with Bayesian forecasting should be considered an invaluable tool for optimizing vancomycin daily exposure in unstable critically ill patients. Int J Antimicrob Agents. 2002;20:326-32 (2002/11/15).

151. Berthaud R, Benaboud S, Hirt D, Genuini M, Oualha M, Castelle M, et al. Early Bayesian dose adjustment of vancomycin continuous infusion in children: a randomized controlled trial. Antimicrob Agents Chemother. 2019;63 (2019/10/09).
152. Cyriac JM, James E. Switch over from intravenous to oral therapy: a concise overview. J Pharmacol Pharmacother [Internet]. 2014;5:83-7. https://www.ncbi.nlm.nih.gov/pubmed/24799810 (2014/05/07).

153. Gasparetto J, Tuon FF, Dos Santos Oliveira D, Zequinao T, Pipolo GR, Ribeiro GV, et al. Intravenous-to-oral antibiotic switch therapy: a cross-sectional study in critical care units. BMC Infect Dis [Internet]. 2019;19:650. https://www.ncbi.nlm. nih.gov/pubmed/31331272 (2019/07/25).

154. de Smet J, Colpaert K, de Paepe P, van Bocxlaer J, Decruyenaere $\mathrm{J}$, Boussery K. Switch from intravenous to enteral moxifloxacin in critically ill patients: a pilot study. Scand J Infect Dis [Internet]. 2012/07/19. 2012;44:874-8. https://www.ncbi.nlm.nih.gov/ pubmed/22804100.

155. McMullan BJ, Andresen D, Blyth CC, Avent ML, Bowen AC, Britton PN, et al. Antibiotic duration and timing of the switch from intravenous to oral route for bacterial infections in children: systematic review and guidelines. Lancet Infect Dis [Internet]. 2016/06/21. 2016;16:e139-52. https://www.ncbi.nlm.nih.gov/ pubmed/27321363. 